\title{
Phase transformation under thermal fatigue of high Mn-TWIP steel: microstructure and mechanical properties
}

\author{
J. J. Roa ${ }^{1,2, *}$, H. Besharatloo ${ }^{1}$, G. Fargas ${ }^{1,2}$, J. Calvo ${ }^{1,3}$, A. Mateo ${ }^{1}$ \\ 1 Departament de Ciència dels Materials i Enginyeria Metal·lúrgica, ETSEIB, \\ Universitat Politècnica de Catalunya, Avda. Diagonal 64708028 Barcelona, Spain \\ ${ }^{2}$ CRnE, Campus Diagonal Sud, Edifici C', Universitat Politècnica de Catalunya, C. \\ Pascual i Vila 15, 08028 Barcelona, Spain \\ ${ }^{3}$ CTM Centre Tecnològic, Plaça de la Ciència, 2, 08243, Manresa, Spain \\ * Corresponding author, e-mail: joan.josep.roa@upc.edu
}

Abstract: High Mn steels present both high tensile strength and good ductility, therefore they have attracted attention as promising candidates for the next-generation of automotive steels. However, slight changes during the manufacturing process or in service conditions (i.e. chemical composition, annealing temperature, among others) can promote significant variations in their microstructure, leading to a strong modification in their mechanical response. In this regard, this paper discusses the relationship between the different microstructures generated on a high Mn-twinning induced plasticity (TWIP) steel and its mechanical properties evaluated by means of Vickers's hardness, tensile testing and also high cycle fatigue response. Different conditions, namely: as received, annealed at $500^{\circ} \mathrm{C}$ and thermally cycled at $500^{\circ} \mathrm{C}$ during $15,36,56$ and 75 cycles, have been analyzed. The results exhibit the development of a heterogeneous pearlitic microstructure with a plateau on its fraction content and Vickers's hardness at $\sim 24 \%$ and $292 \pm 5 \mathrm{HV}$, respectively, after 36 thermal fatigue 
cycles. Finally, pearlite colonies have been nucleated during the thermal fatigue treatment along the austenitic grain boundary producing a deleterious effect on the tensile and high cycle fatigue behaviour.

Keywords: Twinning Induced Plasticity; thermal fatigue; phase transformation; pearlite; tensile tests; high cycle fatigue tests.

\section{Introduction}

Automotive companies are trying to develop vehicles environmentally friendly. Therefore, weight reduction is mandatory to achieve less fuel consumption and also to diminish pollutant emissions. At the same time, vehicles must be safer for passengers. Encouraged by these needs of the automotive industry, in the last decades steel manufacturers have invested efforts to develop new high strength steel grades, such as transformation induced plasticity (TRIP) steels, dual phase (DP) steels, complex phases (CP) steels and, more recently, twinning induced plasticity (TWIP) steels [1]. These latter steels are characterized by high Mn contents (15 to $30 \mathrm{wt} . \%$ ) and they provide a great potential for weight reduction in energy absorption vehicle components, due to their excellent tensile strength and ductility combination $[2,3,4,5,6,7,8]$. The chemical composition and temperature are known to be the main factors in controlling the stacking fault energy (SFE) and, consequently, the main deformation mechanism operative under certain conditions [9,10]. It is considered that when $S F E \leq 20 \mathrm{~mJ} \cdot \mathrm{m}^{-2}$ martensite induced plasticity is favored [10,11], for $S F E \sim 25-60 \mathrm{~mJ} \cdot \mathrm{m}^{-2}$ the martensitic phase transformation is suppressed and mechanical twinning is enhanced [10], and, finally, for $S F E>60 \mathrm{~mJ} \cdot \mathrm{m}^{-2}$ dislocations gliding is the single deformation mechanism. In TWIP steels, the objective is to control the SFE, through specific compositions, to promote twinning as the main deformation mechanism at room temperature. Moreover, this mechanism will also rely on the microstructure, and, in this sense, a fully austenitic 
microstructure is required at room temperature. Therefore, the composition of these steels in $\mathrm{Mn}, \mathrm{C}, \mathrm{Al}$ and $\mathrm{Si}$ contents is adjusted to control the SFE value and stabilize the austenitic phase.

During the last years, an extensive number of investigations on the microstructure evolution of high Mn-TWIP steels have been carried out [1,3,4,12,13,14]. Also their mechanical properties have been investigated: tensile testing $[3,4,15,16,17,18,19,20,21]$, low cycle fatigue and fatigue life $[22,23,24,25]$ and scarce investigations on high cycle fatigue [26]. Furthermore, there are some researches dealing with the effects of thermal and mechanical treatments to modify the austenitic microstructure of those high MnTWIP steels [3,12,13,27]. Van Tol et al. [28] investigated the pearlitic formation during aging in the temperature range $500-600^{\circ} \mathrm{C}$ in undeformed and deformed austenitic manganese-based steel by means of in-situ magnetization measurements and microscopy techniques. Unfortunately, microstructural characterization under thermal fatigue has never been performed for these steels due to their complex microstructures. Moreover, the effects of phase transformation (from austenite to pearlite) under thermal fatigue and their correlation with the mechanical properties of high Mn-TWIP steel have not been systematically studied yet. Within this framework, the major aim of this study was to investigate the effect of thermal fatigue cycles on the duplex (austenitic/pearlitic) microstructure and understanding the correlation between this microstructure and the mechanical properties (hardness at micrometric length scale, tensile testing and high cycle fatigue). A better understanding of the role of the pearlite in austenitic high MnTWIP steel may be an important factor to improve the service lifetime of structural components subjected to thermal cycles at intermediate temperatures in the automotive industry. 


\section{Experimental procedure}

In this work, the studied material was a high Mn-TWIP steel provided by POSCO (South Korea) in the form of sheets of $2 \mathrm{~mm}$ thickness. The chemical composition is presented in Table 1.

Six different sets of specimens were investigated: as received (AR), specimens annealed at $500^{\circ} \mathrm{C}$ during 15 minutes and quenched in air (500Q) and four specimens subjected to thermal fatigue at $500^{\circ} \mathrm{C}$ during $15,36,56$ and 75 cycles, respectively (500-TF15cycles, 500-TF-36cycles, 500-TF-56cycles and 500-TF-75cycles). The thermal fatigue cycle was composed of two different steps: maintaining the specimens at the desired temperature $\left(500^{\circ} \mathrm{C}\right)$ for $1 \mathrm{~h}$ and subsequently air cooling for $20 \mathrm{~min}$. After that, each specimen was first grinded and polished prior the microstructural characterization using silicon carbide paper, polished until $3 \mu \mathrm{m}$ diamond suspension and a final polishing step using a neutral suspension of 20-40 nm alumina particle.

The average grain size and the pearlitic fraction were determined by the conventional linear intercept method and using the imageJ software, respectively; using a total of twenty micrographs obtained by means of field emission scanning electron microscopy (FESEM, Jeol 7001F) at $20 \mathrm{kV}$, in order to have statistical significance.

Thermodynamic calculations were conducted using FactSage ${ }^{\circledR}$ thermo-chemical software [29] to calculate the equilibrium phase fractions as a function of the temperature for the chemical composition presented above. The FSstel database, containing data for solutions and compounds [30], was used. The calculations were carried out in the temperature range between 200 and $1500^{\circ} \mathrm{C}$, every $10^{\circ} \mathrm{C}$ with the search for transition temperatures. 
The response to sharp contact was achieved by the indentation method at microscopic length scale at $1 \mathrm{kgf}$ by means of MKV-HO Akashi hardness tester. Fifteen imprints were done per specimen.

For tensile and high cycle fatigue tests, specimens were machined by laser cutting, with the main axis parallel to the rolling direction. After that, the tensile and fatigue specimens were thermally treated at $500^{\circ} \mathrm{C}$ following the procedure previously described. The main dimensions for the tensile and fatigue specimens are summarized in Table 1.

Tensile tests were conducted until rupture at room temperature and a constant crosshead rate of $3 \mathrm{~mm} \cdot \mathrm{min}^{-1}$ using an Instron 8562 computerized universal machine according to ASTM E 8-04 standard [31]. On the other hand, to eliminate the possible deleterious effects induced by the laser cutting [32], prior to fatigue testing, the surfaces of the fatigue specimens were ground in successive stages by SiC papers from 240 up to 1500 grit to obtain smooth surfaces, and polished mechanically using a diamond suspension with size of $3 \mu \mathrm{m}$ to get mirror finishing. Afterwards, high cycle fatigue tests were conducted under load control mode in a resonant testing machine (Rumul MIKROTRON) according to ASTM E 466-96 [33] standard. Frequencies around 150 $\mathrm{Hz}$ were used and the load ratio was keep constant to $0.1\left(R=\sigma_{\min } / \sigma_{\max }\right)$. The initial maximum stress was taken as $50 \%$ of the ultimate tensile strength $\left(\sigma_{u t s}\right)$ of the corresponding steel condition, directly extracted from the tensile tests. Subsequently, if the specimen was able to reach $10^{6}$ cycles without fail, then $\sigma_{\max }$ value was increased $10 \%$, and so on until fracture, following the staircase method [34], but only with three specimens per condition. Finally, the fracture surfaces as well as the damage induced during tensile and high cycle fatigue tests were examined by FESEM (Jeol-7100F) at 20 $\mathrm{kV}$. 


\section{Results and discussion}

Metallographic evaluation was performed to understand the evolution of the high MnTWIP steel microstructure after the different thermal fatigue tests at $500^{\circ} \mathrm{C}$. Five specimens were analyzed corresponding to the as received specimen (Figure 1a) and after different number of thermal cycles: 15, 36, 56 and 75 (Figures $\mathbf{1 b}$ to 1e). The preliminary characterization of the annealed specimen, not subjected to thermal cycling, revealed polygonal and equiaxal grains for the as received specimen with an average grain size of $6.2 \pm 1.5 \mu \mathrm{m}$, with the presence of some annealing twins. The specimen thermally fatigued during the lowest number of cycles (Figure 1b) presented some islands of pearlite phase (see white arrows), reaching a fraction of around $7.2 \pm 4.2 \%$. The big scatter associated with this measurement is related to the heterogeneous nucleation and growing process of the pearlitic phase. Electron microscopy images corresponding to other specimens with a higher number of cycles and located close to pearlitic colonies are depicted in Figures 1c to 1e. The amount of pearlitic phase created during the thermal fatigue experiment reached a value of around $24 \pm 2 \%$ after 36 cycles, which remained almost unaltered for the two longest treatments. For these specimens, the average grain size was not determined due to the difficulty to clearly distinguish the grain boundaries at the pearlitic colonies.

It is well known that the pearlitic microstructure of steels and cast irons $[35,36]$ presents a layered microstructure composed of alternating layers of $\alpha$-ferrite and cementite. This microstructure can be appreciated in Figure 2, corresponding to a totally pearlitic zone of a specimen subjected to 75 cycles. As seen in this figure, the orientation of the pearlite layers vary from one grain to another because the pearlitic phase is strongly dependent on the crystallographic orientation of the original phase from which it transforms. A similar finding has been recently observed by van Tol et al. [28]. 
Thermodynamic analysis using FactSage ${ }^{\circledR}$ software for the high Mn-TWIP steel studied here (Figure 3a) elucidated that the original austenitic phase may decompose into a duplex microstructure (mainly austenitic and pearlitic) at temperatures around $600^{\circ} \mathrm{C}$, although the maximum volume fraction of this phase is found at $500^{\circ} \mathrm{C}$ and below. Therefore, a fully austenitic microstructure for Mn based steels is in a metastable state at temperatures below $600^{\circ} \mathrm{C}$. This result is totally in agreement with the work reported by van Tol and co-workers [28], pointing out that slight chemical changes in the composition of TWIP steels do not modify the partial transformation to pearlite. According to the dynamic calculations, the carbides which form during the pearlitic transformation are mainly $\mathrm{Mn}_{3} \mathrm{C}$, as shown in Figure $\mathbf{3 b}$.

According to Figure 3a, the maximum mass fraction of pearlite at $500^{\circ} \mathrm{C}$ should be around $60 \%$. This value is not reached during the thermal cycling of the material, which shows a saturation of pearlite at 24 weight \%. According to Tol et al. [28] the equilibrium value is not reached because the partition of Mn from the austenite to the pearlite is incomplete. They claim that the equilibrium state reached after annealing condition (or thermal cycling conditions in the present study) is a combination of paraequilibrium between the austenite and the pearlite and orthoequilibrium between the ferrite and the cementite. In fact, the diffusion of $\mathrm{Mn}$ in the austenite is limited to length scales of the order of $10 \mathrm{~nm}$, which prevents orthoequilibrium to be reached between the austenite and the pearlite, whereas in the ferrite the diffusion of $\mathrm{Mn}$ is an order of magnitude higher.

Given the contents on microalloying elements such as $\mathrm{Ti}$, $\mathrm{Nb}$ and $\mathrm{V}$, thermodynamic calculations were also carried out to determine the possible presence of particles in the microstructure. According to the results (Figure 3c), different carbonitrides can form, being $\operatorname{Ti}(\mathrm{C}, \mathrm{N})$ the ones forming at the highest temperatures, i.e. since the solidification 
of the alloy. This is in accordance with the results previously reported by the authors [36] showing the presence of these particles in the microstructure. From the point of view of austenite decomposition to pearlite due to thermal cycles, these particles should be considered as possible nucleation points.

Vickers's hardness histogram is represented in Figure 4 for the AR and thermally fatigued specimens. Hardness increases from its initial value of $232 \pm 3 \mathrm{HV}$ for the AR sample up to almost $300 \mathrm{HV}$ for those specimens whose pearlitic fraction was around $24 \%$, i.e., those thermally fatigued for 36 cycles or more. Vickers's hardness increases with the pearlitic content because this phase, formed by ferrite and cementite layers, blocks the dislocation motion and the deformation of the ferrite is restricted in regions adjacent to the phase boundary.

The true stress $(\sigma)$ - true strain $(\varepsilon)$ curves for all the studied specimens are represented in Figure 5a. It can be seen that the yield strength, ultimate tensile strength and total elongation for the specimens of interest are strongly dependent on the microstructure, as summarized in Table 2. Specimens with a fully austenitic microstructure (AR and 500Q) presented a very high ductility, with elongation values higher than $90 \%$. However, this ductility was strongly reduced for all specimens thermally fatigued. Due to the presence of pearlitic colonies, their range of elongation values dropped to 17 $23 \%$. It is important to highlight that even for specimens with the lowest percentage of pearlite (500-TF-15 cycles) the ductility decreased at the same level than for specimens subjected to higher number of thermal cycles. On the other hand, the presence of the pearlitic content in the specimens thermally fatigued produced a significant increase of the yield strength, of around $100 \mathrm{MPa}$, as shown in Table 2. The contrary can be said about the ultimate tensile strength, which is around $100 \mathrm{MPa}$ higher for totally austenitic specimens. After 75 thermal cycles the yield strength is maximum and the 
ductility is significantly reduced. This behavior cannot be attributed to an increase of the pearlite mass fractions, which is constant after 36 thermal cycles. Therefore, this change in the monotonic tensile behavior could be related to a change of the morphology of the pearlite, although this point should be further addressed.

As it can be appreciated in detail in Figure 5, several micro-serrations events for the AR and 500Q specimens are appreciable. These events are very common in the high MnTWIP steels containing $\mathrm{C}$ and have been reported previously by several researchers elsewhere [Error! No s'ha definit el marcador.,37,38,39,40], being attributed to dynamic strain aging (DSA). Jin et al. [15] observed that this phenomenon is strongly related to the $\mathrm{Al}$ content present in the high Mn-TWIP steel. Furthermore, these serrations events occur as a result of the generation and propagation of Portevin LeChatelier (PLC) bands, as several authors observed elsewhere [37,39,41]. The principle of PLC effect is DSA associated with the interaction between mobile dislocations temporally blocked at localized defects. Then, this effect is due to pinning and unpinning of dislocations by interstitial atoms of $\mathrm{C}$ and $\mathrm{N}$ in the austenitic microstructure, as reported De Almeida and co-workers [42].

Fracture surfaces for the studied conditions analyzed by FESEM are shown in Figure 6. Specimens with an austenitic microstructure, i.e., AR and 500Q, displayed a totally ductile fracture, as it can be seen in Figures $\mathbf{6 a}$ and $\mathbf{6 b}$, where dimples are clearly identified. The fracture surface morphology was quite different for specimens subjected to thermal fatigue, even for the steel condition with only $7 \%$ of pearlite phase (Figure 6c). For these austenitic-pearlitic microstructures, fracture has a mixed brittle-ductile aspect (Figure 6c and 6d). When some areas on those fracture surfaces are seen at a higher magnification (Figure 7), a totally brittle aspect is revealed which is related to the presence of pearlitic colonies. 
It is important to point out the existence of inclusions for both types of fracture surfaces (see black arrows in Figures 6a, 6b and 6c). These particles can be easily identified as TiN given their square shape. Their presence was also shown in previous work [43] and thermodynamic calculations (Figure 3b) confirm the easiness of their formation.

Figure 8 summarizes the fatigue life trend displayed for the studied steel conditions. As can be appreciated, there are two different trends; one for the AR and 500Q specimens where no pearlite has transformed and the other for the specimens thermally treated where a duplex microstructure ( $\gamma /$ pearlite) was observed. The specimens with an austenitic microstructure resist a high number of fatigue cycles, while for the specimens with a duplex microstructure the resistance to fatigue decreases significantly. As it can be observed in this group, the specimens thermally fatigued during 15 cycles resist more than the other specimens due to the pearlitic content distributed inside the specimen. The thermally treated specimens with the same content of pearlite (36 up to 75 thermal fatigue cycles) resists a similar number of fatigue cycles, pointing out that the microstructure is the limiting parameter under this working conditions. Thus, the trend is similar than those reported for the specimens tested under monotonic loading and presented in Figure 5.

A detailed FESEM fractographic examination of samples broken under cyclic loads pointed out the presence of critical defects of similar nature and geometry to those observed in specimens subjected to tensile tests and depicted in Figures 5 and $\mathbf{6}$. Under the application of cyclic loads, these defects act as locations for microcracks nucleation (Figure 9). This deleterious influence of TiN was discussed in previous papers by the authors [32,Error! No s'ha definit el marcador.].

\section{Conclusions}


From an analysis of the experimental results obtained in this investigation, the following conclusions can be drawn:

The annealing treatment at intermediate temperatures does not modify the initial austenitic microstructure of TWIP steels. However, specimens thermally fatigued at $500^{\circ} \mathrm{C}$ present pearlitic colonies heterogeneously distributed. Phase transformation from austenite to pearlite reaches a maximum content of around $24 \%$ after 36 thermal cycles.

Vickers's hardness and pearlitic contents follow a monomolecular growth function.

The stress-strain curves are strongly dependent with the pre-existing microstructure, showing a ductile behavior for the totally austenitic steel those changes to a brittle behavior for the duplex microstructure (austenitic/pearlitic).

Several micro-serrations in the stress-strain curve were observed for the specimens with austenitic microstructure, as a result of the generation and propagation of a Portevin LeChatelier bands.

The specimens with the highest pearlitic content (after 75 thermal fatigue cycles) presents the highest yield strength $(\sim 58 \%)$ compared with those where the steel presented a fully austenitic microstructure (AR and 500Q). TiN inclusions and pearlitic colonies are the main microstructural features responsible of the fracture process for specimens tested under monotonic tensile conditions.

Duplex microstructure (austenitic/pearlitic) has lower strength than the original austenitic microstructure. This can be attributed to the brittle nature of the secondary phase created during the thermal fatigue treatment. 
At the same time the internal defects (i.e. TiN inclusions) heterogeneously distributed in the specimens also govern the lifetime for all the specimens investigated under high cycle fatigue assays.

\section{Acknowledgements}

The authors greatly acknowledge I. López Insa from the "Laboratori de Microscopia Electrònica del CMEM-UPC” for his contribution to the FESEM image analysis. Moreover, we would like to thank POSCO (South Korea) for supplying the material of this study.

We are grateful to "Direcció General de Recerca del Comissionat per a Universitats i Recerca de la Generalitat de Catalunya” for recognizing CIEFMA (2014SGR130) and PROCOMAME (2014SGR1416) as consolidated Research Groups. One of the authors (J.J.Roa) would like to thank the Juan de la Cierva programme (Grant number: JCI2012-14454) for financial support.

\section{References}

[1] L. Bracke, K. Verbeken, L. Kestens, J. Penning, Acta Mater. (2009); 57:1512.

[2] G. Frommeyer, U. Brüx, P. Neuman, ISIJ Int. (2003); 43:438.

[3] O. Grässel, L. Krüger, G. Frommeyer, L. W. Meyer, Int. J. Plast. (2000); 16:1391.

[4] D. Barbier, N. Gey, S. Allain, N. Bozzolo, M. Humbert, Mater. Sci. Eng. A. (2009); 500:196.

[5] S. Curtze, V. T. Kuokkala, Acta Mater. (2010); 58:5129.

[6] B. C. De Cooman, O. Kwon, K. G. Chin, J. Mater. Sci. Technol. (2012); 28:513.

[7] A. Saced-Akbari, L. Moseeker, A. Schwedt, W. Bleck, Metall. Mater. Trans. A. (2012); 43:1688.

[8] A. Saced-Akbari, A. Schwedt, W. Bleck, Scripta Mater. (2012); 66:1024. 
[9] L. Kruger, L. W. Meyer, U. Brüx, G. Frommeyer, O. Grässel, J. Phys. IV. (2003); 110:189.

[10] S. Allain, J. P. Château, S. Allain, S. Migot, N. Guelton, Mater. Sci. Eng. A. (2004); 387-389:158.

[11] B. W. Oh, S. J. Cho, Y. G. Kim, Y. P. Kim, W. S. Kim, S. H. Hong, Mat. Sci. Eng. A. (1995); 197:147.

[12] S. Vercammen, B. Blanpain, B. C. De Cooman, P. Wollants, Acta Mater. (2004) ; 52: 2005.

[13] H. Ding, Z. Y. Tang, W. Li, M. Wang, D. Song, J. Iron Steel Res. Int. (2006); 13:66.

[14] S. Allain, J. P. Château, D. Dahmoun, O. Bouaziz, Mater. Sci. Eng. A. (2004); 387389:272.

[15] J. -E. Jin, Y. -K. Lee, Acta Mater. (2012); 60:1680.

[16] G. Dini, A. Najafizadeh, R. Ueji, S. M. Monir-Vaghefi, Mat. Design. (2010); 31:3395.

[17] L. A. Dobrzanski, A. Grajcar, W. Borek, Archi. Mater. Sci. Eng. (2009); 2:69.

[18] C. Song, W. Lu, K. Xie, Y. Zhang, W. Xia, K. Han, Q. Zhai, Mat. Sci. Eng. A. (2014) ; $610: 145$.

[19] Y. Zhao, J. Wang, S. Zhou, X. Wang, Mat. Sci. Eng. A. (2014); 608:106.

[20] D. Hua, T. Z.- You, L. Wei, W. Mei, S. Dan, J. Iron Steel. Res. Int. (2006);13:66.

[21] L. A. Dobrzanski, W. Borek. J. Achieve, Mat. Man. Eng. (2012); 55:230.

[22] Y. -X. Wu, D. Tang, H. -T. Jiang, Z. -L. Mi, Y. Xue, H. -P. Wu, J. Iron Steel Res. Int. (2014); 21:352.

[23] P. Guo, L. Qian, J. Meng, F. Zhang, L. Li. Mat. Sci. Eng. A, (2013) ; 584 :133.

[24] Y. W. Kim, G. Kim, S. -G. Hong, C. S. Lee, Mat. Sci. Eng. A. (2011); 528:4696. 
[25] A. S. Hamada, L. P. Karjalainen, J. Puustinen, Mat. Sci. Eng. A. (2009); 517:68.

[26] A. S. Hamada, L. P. Karjalainen, Mat. Sci. Eng. A. (2010); 527:5715.

[27] W. D. Callister. Introducción a la ciencia e ingeniería de los materiales. Reverte, 2002, vol. 1. ISBN : 8429172521.

[28] R.T. van Tol, L. Zhao, J.Sietsma. Acta Mater. (2014);64:33.

[29] FSstel database, in: www.factsage.com (visited, 08/12/2015).

[30] C.W.Bale, E.Bélisle, P.Chartrand, S.A.Degterov, G.Eriksson, K.Hack, I.H.Jung, Y.B.Kang, J.Melancon, A.D.Pelton, C.Robelin, S.Petersen, Calphad (2009); 33:295.

[31] ASTM E8-04: Standard test methods for tension testing of metallic material) 2008.

[32] A. Mateo, G. Fargas, J. Calvo, J.J.Roa. Mat. Testing (2015);57:136.

[33] ASTM E466-96. Standard Practice for Conducting force Controlled Constant Amplitude Axial Fatigue Tests of Metallic Materials, 2002.

[34] J. A. Collins. Failure of materials in mechanical design. New York, USA: John Wiley \& Sons Inc; 1981. pp. 369-374.

[35] D. Raabe, P. P. Choi, Y. J. Li, A. Kostka, X. Sauvage, F. Lecouturier, K. Hono, R. Kirchheim, R. Pippan, D. Embury, MRS Bull. (2010); 35:982.

[36] Y. J. Li, P. P. Choi, C. Borchers, S. Westerkamp, S. Goto, D. Raabe, R. Kirchheim, Acta Mater. (2011); 59:3965.

[37] L. Chen, H. S. Kim, S. K. Kim, B. C. De Cooman, ISIJ Int. (2007); 47:1804.

[38] M. N. Shickhelsouk, V. Favier, K. Inal, M. Cherkaoui, Int. J. Plast. (2009); 25:105.

[39] Y. N. Dastur, W. C. Leslie, Metal. Trans. A. (1981); 12A:749.

[40] L. J. Cuddy, W. C. Leslie, Acta Metal. (1972); 20:1157.

[41] P. H. Adler, G. B. Olson, W. S. Owen, Metal. Mater. Trans. A. (1986); 17A:1725.

[42] L. H. De Almeida, I. Le May, P. R. O. Emygdio, Mater. Charact. (1998); 41:137. 
[43] J. J. Roa, G. Fargas, J. Calvo, E. Jiménez-Piqué, A. Mateo. Mat. Sci. Eng. A. (2015); 628:410. 